\title{
Creative Destruction in the PC Industry
}

\author{
Timothy Bresnahan
}

Presented to the Conference on IT Innovation, Tokyo, December 2004.

IIR Working Paper WP\#05-03

J une, 2004

Institute of Innovation Research

Hitotsubashi University

Tokyo, Japan

http://www.iir.hit-u.ac.jp 


\title{
Creative Destruction in the PC Industry
}

\author{
Timothy Bresnahan * \\ June, 2004 (This Version, December 2004)
}

* Stanford University. http://www.stanford.edu/ tbres/ I would like to thank Shane Greenstein, Rebecca Henderson, Franco Malerba, and Manuel Trajtenberg for many helpful comments. My collaboration with Greenstein and Henderson has been particularly useful in creating the analytical frame used in this industry study. 


\section{Introduction: Because it is there! Why?}

The personal computer industry offers a marvelous opportunity to study creative destruction. Over its first twenty years, the industry experienced a number of Schumpeterian waves of creative destruction. Each wave involved many of the distinct markets in the industry. Waves struck established dominant firms in hardware, in software and networking, in general purpose technologies and in applications. While not numerous enough for systematic statistical analysis, the many instances of wave*market present an opportunity to think analytically about the causes and consequences of creative destruction. The waves of PC industry creative destruction stopped ten years ago. Even though occasions for waves continued, creative destruction of established firms' positions in the most strategic PC markets ceased.

The PC industry offers us the chance to see how creative destruction occurs. It also lets us distinguish analytically between circumstances permitting creative destruction and other circumstances blocking it.

\section{A. Technology and Demand}

Any analytical enquiry into creative destruction must answer a series of "Why?" queries, and this is no exception. Schumpeter observed that competition from new commodities, new technologies, new sources of supply, and new types of organization is particularly important for long run growth. ${ }^{\dagger}$ That normative observation speaks to the social value of creative destruction.

Sometimes we interpret the normative observation as also providing a positive theory of creative destruction. Why are there Schumpeterian waves? Because they crucial to growth! Yet that is seriously incomplete. It does not answer what changes occur in technology or demand to make a wave of creative destruction part of the socially desirable innovation path. Even more important, the normative observation does not answer critical positive questions. Why do waves occur at particular times in particular markets? What moves an industry from a regime of repeated waves of creative destruction to a regime of persistent dominant firms?

To address these questions in the PC industry entails key aspects of technology and demand. At the heart of PC technical progress is Moore's law, a quantitative engineering prediction about the rate of improvement in microelectronic components. Moore's law has been a driver of change since the beginning of the PC industry. Many PC industry participants correctly see it as driving opportunities for ongoing improvement in things like software (not itself subject to Moore's law.) There must, however, be more to the story. Moore's law suggests a continuous stream of innovation, not a serious of waves of creative destruction. And careful measurements suggest Moore's law increased in speed about a decade ago, just as the waves of creative destruction ceased. Market analysis, not technical determinism, is needed to explain the early waves and the later cessation.

Other consideration of demand and technology in the PC industry raise more questions about creative destruction. Demanders and inventors in the PC industry make

† Schumpeter (1942), pp. 82-85 (page cite to 1975 Harper edition.) In addition to "waves” Schumpeter called such times "revolutions." Computer industry leaders sometimes say "strategic inflection point" or "paradigm shift" wanting to suggest something revolutionary and technical. 
sunk investments that add costs to radical change. Demanders and inventors prefer new products or technologies with "backward compatibility," i.e., ones that can be used without abandoning already sunk investments. A consumer who bought a new word processor, for example, would prefer it to read old files, run on existing computers, and accept old commands. Similarly, an applications developer would prefer that new computers run existing programs. Backward compatibility is a conservative force, that leads quickly to the question, why did the PC industry have so many waves of creative destruction?

More generally, any enquiry into creative destruction in the PC industry should understand why and how technology and demand change over time to call forth waves of creative destruction.

\section{B. Organizations}

Schumpeterian enquiry links waves of creative destruction to organizational capabilities and incentives. ${ }^{\ddagger}$ An essential feature of a wave is that new firms create and existing dominant firms are destroyed. This observation, too, leads to a chorus of "why?"

Why did existing established firms not invent the new technology? Why, instead, must new firms be the innovators who set off a wave of creative destruction? The answer to this query could arise because of limitations on the abilities or knowledge of existing firms. They may not see opportunities for advance which are, instead, seen by entrants. Satisfactory discussion of this answer by scholars calls for first learning precisely what it was that existing firms did not see, and second for adopting an ex ante invention perspective in order to understand why they did not see it. The answer to this query could also arise in incentives. Established firms may have seen the technological opportunity but not had an incentive to take it up, while entrants' incentives are the reverse. Satisfactory discussion of this answer calls for careful statement of why and how the incentives varied at the decision moment(s).

One simple organizational theory posits that entrepreneurs are innovative, while established dominant firms are less so. Another theory posits (exogenous?) technical and market eras; firms that are strong in one era are weak after the changes that usher in the new era. Of course, it is logically possible that the market is selecting the most suitable firm both before and after each wave of creative destruction. Then the timing of arrival of new and better firms explains the timing of waves. But that is not the only logical explanation. Another is that entry barriers keep out more suitable firms before a wave; creative destruction arises when entry barriers fall.

These organizational questions have to be answered with care and precision in the PC industry, for there are many different phenomena. In Figure 1, I sketch the history of dominant firms in a number of important PC markets.

The Figure makes it clear that we cannot use only the simple theory that entrepreneurial firms see new opportunities while established firms see only existing ones. Consider the history of the spreadsheet and word processor markets. Each has had three dominant firms over three distinct eras. All of the dominant firms shown in the Figure are entrepreneurial firms that think of themselves as forward-looking and innovative. How should we explain the role of the "middle" firms, Lotus (spreadsheets) and

\footnotetext{
₹ See Henderson (1993), Henderson and Clark (1990) and Christenson (1997). Incentives-based theories related to creative destruction are reviewed in Reinganum (1989).
} 
WordPerfect, which are successes in creative destruction just a few years before they are swept away by it?

Another problem can be seen by looking at the PC market row itself in the Figure. Most of the firms successful in the early PC industry or, indeed, successful in it today, are youngish entrepreneurial firms that think of themselves as more forward looking than the "dinosaurs" of the traditional computer industry, like IBM. In light of that, how should we understand the core event of the industry's first wave of creative destruction, the entry of IBM with the IBM PC in 1981?

I am not singling out organizational capabilities explanations here. Similar problems apply to incentives explanations. The Office suite of personal productivity programs is the most valuable monopoly in history. ${ }^{\S}$ That casts real doubt on a simple incentives theory of the most recent wave of creative destruction. Why did Microsoft have an incentive to introduce Word and Excel, the components of Office, while Lotus and WordPerfect, makers of the predecessor applications, did not? To assume they did seems an implausible theory. My point here is not to discard either organizational theories or incentives ones, and certainly not both. My point is that any answer to "Why did established firms miss the waves?” needs to be stated with precision.

\section{Threats and Policies}

Schumpeter observed that the threat of creative destruction can give powerful incentives to incumbents. Instead of waiting to be destroyed, an incumbent should act as soon as the threat appears; in that manner, the incumbent is disciplined by the threat of creative destruction. This leads to the logical possibility that actually completed creative destruction is not, strictly speaking, necessary. Perhaps entrants can play their role as creators and changed incumbent incentives can rid society of wasteful destruction.

This argument seems to have at least two shortcomings. One is why entrants have the incentive to take costly actions to attempt creative destruction. If they will not succeed, but instead merely serve as an example and a threat, how much resources should go into creation? Similarly, if an entrant has created valuable new technology, why o into competition with well-positioned incumbents instead of selling out to them? Many of our colleagues think that such incentives are very limited, and that the supply of entrant / outsider technologies is largely volunteers, such as entrepreneurs in garages, scientists, or the excessively optimistic. A modern example in the PC industry might be the open source movement. The same logic would also provide an explanation of why creative destruction is rare - if not why it was so common for so long in the PC industry.

A second problem with the "mere threat" approach arises with incumbent incentives or with organizational heterogeneity. Clearly the threat of creative destruction is an incentive for incumbents. If, however, incumbents can always respond to threats and evade destruction, is that incentive weakened? And if incumbents and entrants are fundamentally different organizations, is the mere threat of creative destruction

\footnotetext{
$\S$ Obviously, this is undiscounted. If the Bourbon monarchy had cashed out in, say, 1760, and invested the money at reasonable rates of interest, it would today be worth more than Office.

${ }^{* *}$ Gans, Hsu, and Stern (2002) provide an argument, based on the opportunities for contracting between entrants and incumbents, why creative destruction is rare, and considerable evidence that it is in general rare. I shall return to the reasons why the PC industry was exceptional below.
} 
sufficient? Will there not sometimes be advantages of replacing one organization with another, better suited to new technological or market circumstances?

Schumpeter also argued that large established firms can be important engines of growth, perhaps more important than creative destruction by outsiders. ${ }^{\dagger \dagger}$ This argument would interact positively with the "mere threats" theory. We might have a market in which large established firms, with all their resources and market connection, successfully innovate themselves and also successfully respond to the threat of creative destruction.

The frequency of creative destruction is sometimes explained by analysis of government support of innovation, for example, through patent policy. An entrant might have a patent on a superior technology, for example, spurring a wave. Yet government protections for innovation have been unimportant in the PC industry, both at times when there has been a great deal of creative destruction and at times when there has been less. Like incumbents, entrants have had little protection from patents, copyrights, or the like. Firms have relied far more on trade secrets.

Another Schumpeterian policy debate swirled in the PC industry recently. In its landmark antitrust case, the US government accused Microsoft of blocking creative destruction in order to avoid competition. Critics of the case, such as Richard Schmalensee, suggested that the government simply did not understand "Antitrust Issues

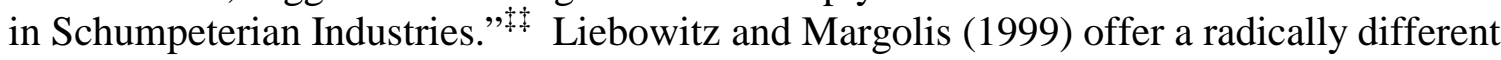
view of the sources of Schumpeterian competition in the PC industry than you will find here. However you see it, creative destruction is not the stuff or empty academic debate, but of immediate importance to growth and to policy.

The phenomenon of creative destruction is there. In the PC industry, the key positive questions are "Why was the pace of creative destruction so fast?" And "Why did creative destruction cease?” I begin to answer them by looking at the first wave of creative destruction in the industry.

\section{A Wave, Preceded and Proceeding}

The PC industry was founded in 1975. A wave of creative destruction began in 1981 with the introduction of the IBM PC. While the consequences of the creative destruction took longer to play out in some PC industry markets than in others, they were far reaching. The dominant sellers of word processing programs, spreadsheets, operating systems, and computers, among others, were all replaced within a few years. All of these were entrepreneurial firms, and most had won difficult competitive races to gain their dominant position. In this section, I first discuss the conditions that preceded the wave, then analyze the creative destruction itself.

\footnotetext{
†† Schumpeter (1911).

㧊 That is the title of Schmalense (2000).
} 


\section{A. Preceding a Wave}

The story of the PC industry shortly after its founding is familiar, and we need only retell it an economic perspective to see the essential features of the time before a wave of creative destruction. ${ }^{\S \S}$

The founding of the PC industry was based in the entrepreneur innovation of firms like Intel (invented the microprocessor) MITS (founded the industry with a PC kit) and Microsoft (wrote a programming language, BASIC, for the first PCs). The initial industry sold primarily to hobbyists, i.e., very technically fluent users.

Entrepreneurial Apple introduced fully assembled personal computers and sold them primarily to home and hobbyist users. Apple encouraged outsiders, developers of applications software, to write programs for its computer. Commercially-oriented Apple focused particularly on encouraging the supply of computer games and home applications. Supply was vertically disintegrated, and the well documented and open interface between the Apple and applications meant that anyone could write an application and attempt to gain widespread distribution for it. ${ }^{* * *}$

Similarly, the entrepreneurial sellers of the $C P / M$ operating system encouraged a wide variety of complementary inventions to go with their product. ${ }^{\dagger+}$ Their OS ran on many different brands of computer. They encouraged innovation by computer makers and by developers of applications. Since much of the demand was from hobbyists or from hobbyist-entrepreneurs seeking to make small business computers, CP/M's makers encouraged the development of hardware and software that would be useful to such demanders. Like Apple, one of their most important tools of encouragement was an open and well documented interface between $\mathrm{CP} / \mathrm{M}$ and applications programs.

One factor that makes the PC industry easier to study is the extensive public discussion of interface standards, extensive technical discussion that crosses firm boundaries. Information that might be inside the firm in another industry is publicly discussed in this one. One reason is network effects, which give PC firms selling GPTs (such as the Apple II or CP/M) an incentive to collaborate with many other firms. ${ }^{\text {抹 }}$

While there were other kinds of personal computer in that era, Apples and CP/M machines were dominant platforms reinforced by network effects. The idea of buying the same standard as other users emerged in the trade press of the time. For application developers, the idea of writing applications for the same standard as other developers emerged as well. Non-compatible kinds of PCs declined in importance at the expense of

$\S \S$ Throughout this paper, I draw heavily on histories of the computer industry that treat the PC industry in detail, such as .Campbell-Kelley and Aspray (1996) and Chandler (2001). I also draw heavily on works of very careful journalism, such as Freiberger and Swaine (2000) and Manes and Andrews (1993).

${ }^{* * *}$ While Apple sold both hardware and software, other firms sold widely distributed products such as spreadsheets and word processors.

${ }^{+T+}$ Thus the supply of complete CP/M systems was even more vertically disintegrated than that of Apples. In what follows, I shall often use vertically disintegrated supply as a shorthand for the vertically disintegrated supply of widely used components.

执 Network effects is a large area of economics and very important to the PC industry. The most recent and complete survey is in Farrell and Klemperer (2001) in volume three of the Handbook of Industrial Organization. See also the online bibliography at Nicholas Economides' web site. A very accessible summary is in Shapiro and Varian Information Rules (1998). The Journal of Economic Perspectives 1994 special issue had survey essays from three perspectives, notably Besen and (1994), Katz and Shapiro(1994), and Liebowitz and Margolis (1994). The idea goes back to Veblen’s (1896)

"bandwagon" theory of demand. 
the two leading platforms. While there was competition between these two platforms, network effects inertia was setting in around them. Users would be well served to choose one of these two platforms because many developers were making applications for them, and developers would be well served to choose them because they had the most users.

Demand for PCs at the beginning was quite different from later on. Early demanders were hobbyists, players of games, home users and to some extent small business. The PC was a general purpose technology. Its early entrepreneurial sellers had purposes in mind, including hobby use, games, multimedia authoring, personal liberation, and home use. For example, many technical features of the Apple II were designed with games in mind. The PC was also invented with the idea that unforeseen applications would be invented. It was designed to permit a wide range of applications not foreseen at the time. The openness and expandability of the Apple II come immediately to mind as an example.

\section{B. Office Applications}

Two important innovations, the spreadsheet and the word processing program, opened up a new and even larger market for PCs. We now think of this market, white collar workers, as the main market for PCs, but that was not obvious in the 1970s. Neither of these innovations came from Apple or the sellers of CP/M, nor were there close contractual links between the sellers of standard platforms and the inventors of the newest applications. Instead, the spreadsheet VisiCalc was invented by a student and commercialized by him and partners. Dominant word processing program WordStar also had entrepreneurial origins; the entrepreneur had been marketing director at a firm selling personal computers.

The impact of the invention of these office applications was to substantially raise the demand for PCs. In particular, VisiCalc led to the sales of a large number of Apple II computers to white collar number crunchers, and WordStar led to the sales of many $\mathrm{CP} / \mathrm{M}$ machines for the use of white collar typists.

Many people, both scholars and industry participants, have noted one of the general lessons about innovation and organization here. The open and modular design of PCs and the vertical disintegration of the PC industry were important to this innovation. Innovation in the early PC industry arose from a wide number of different firms. Different complements were invented in different firms (and sometimes emerged from a competitive struggle among several firms). ${ }^{\S \S \S}$ Openness, modularity, and vertical disintegration worked to facilitate a positive feedback system. The invention and improvement of applications raised the demand for PCs, and the invention and improvement of PCs raised the demand for applications.

If we differentiate among classes of applications, distinguishing office applications from games, we can see a second, less familiar, lesson from this history. The PC was a general purpose technology invented without any foresight about its most valuable applications for many years, like word processing and spreadsheets. Indeed, many early inventors in the PC industry detested the idea of the PC serving as a tool for white collar workers doing ordinary bureaucratic work in corporations. Yet that was the most valuable use of the PC during much of the growth of the industry over the 1980s and early 1990s. The invention of the PC itself was recombined by applications

\footnotetext{
$\S \S \S$ See Langlois (2002) and Langlois and Robertson (1992).
} 
inventors to make what we now know of as a familiar technology, the white collar office PC. It went beyond, and in many cases against, the goals of earlier inventors.

This is an important general point. The most economically important use of a general purpose technology need not be determined by the inventors of the GPT, but rather by the inventors of complements, applications. Recombination of GPTs gives them new markets as well as new technical life.

Recombination arose from the ex post flexibility and permissiveness of markets. Rather than following a path planned out by any firm or any group of firms, the PC industry followed a circuitous route to its most valuable growth market. Many inventors changed the direction of the industry by changing its relationship to markets.

This is illustrated in Figure 2, which shows three flows of causation. Invention of general purpose technologies enables the invention of useful applications. Applications invention and GPT invention have positive feedback. Applications can recombine GPTs, bringing them into new markets.

\section{A wave enabled}

The early sponsors of the Apple II and CP/M PC platforms benefited from the increased demand caused by applications innovation. They also suffered competitively after applications innovation changed the industry in a way that permitted new entry and competition against them.

The successful commercialization of spreadsheets and word processors revealed a growth market, white collar workers in corporations. At the same time, rapid technical progress in microprocessors and other underlying technologies made improvements to PC possible. A new market plus new technological opportunity laid the foundation for creative destruction.

We sometimes think of the instigator of creative destruction as an entrepreneur or other new entity. In the first big wave of PC creative destruction, it was an outsider of another kind. IBM, long the dominant seller of corporate computing, saw the opportunity and entered. PCs would now be bought by IBM's traditional customers, corporations. A computer with "IBM" on it would sell well.

We sometimes think of the firms threatened by a wave of creative destruction as old and slow. The firms selling Apples and CP/M were, on average, five years old when the first wave of creative destruction arrived. It is wrong to think of them as uninteresting in or uninformed about the growth possibility afforded by new corporate customers, for they were pursuing it. Instead, the rapid change associated with an unanticipated shift in demand for their product, plus the entry of as formidable a market competitor as IBM, left them in a very difficult spot.

Early PCs were designed with hobbyists or home users in mind, not white collar workers. The first Apple II, for example, had 40 columns of text, poor for word processing. More generally, the early PC design traded off ease-of-use and power in a a different way than most corporate users would prefer. The gap between what PCs could

\footnotetext{
**** The idea that recombination is an important part of technical progress is in Schumpeter (1911). See also Weitzman (1998) for an economic theory of recombination and Fleming (2001) for a managerial view. Fleming also has cites to the historical literature. Varian (2003) makes the argument that recombination is important in computing.
} 
do and what the newest demand segment wanted gave the young incumbent dominant firms a difficult technical and business problem.

Apple moved quickly to make a PC more suitable for white collar use, and introduced the Apple III before IBM entered. This was a sound strategy, but the Apple III was an implementation disaster, failing frequently in the field. The sellers of CP/M decided to innovate their way out of trouble, designing a radical improvement with a number of new features they thought would be valuable in corporations. This meant, however, that they were slow to market, leading at first to complaints from complementors and then to market disaster.

\section{A wave}

IBM entered with a vertically disintegrated structure and an incremental computer design. It was backward compatible with $\mathrm{CP} / \mathrm{M}$ machines, meaning that applications and hardware add-ons for CP/M machines could easily be adapted to use with the IBM PC. Better microprocessors would have permitted a technical leap forward in the IBM PC. But IBM chose not to take that path, and the keys to IBM's creative destruction were IBM's reputation with corporate customers, quick “porting” of existing applications to the IBM PC and, later, new applications that ran only on the IBM PC.

Why was IBM able to enter the personal computer business so quickly? An important element was the vertically disintegrated structure of the existing PC industry. IBM invented a new computer, but contracted with existing PC industry firms for many of the key components. Indeed, the leading sellers of microprocessors, printers, disk drives, programming tools and spreadsheet software worked with IBM. While the leading operating system vendor did not work with IBM, IBM was able to enter with a clone of their product, CP/M. (Formal intellectual property protection rights were weak, and the threatened lawsuit by the inventors of $\mathrm{CP} / \mathrm{M}$ was ineffectual.) The leading word processor vendor at first also refused to work with IBM, but switched after the IBM PC began to succeed.

There was another advantage to entrant IBM from the vertically disintegrated and open PC industry, which was backward compatibility. Users and developers could migrate to the IBM PC without losing their sunk investments. While the sellers of CP/M would have like to prevent that, they were badly posed to do so. They could not prevent key complementors from working with IBM, since those key complementors were in other firms and linked, if at all, only by weak contracts.

The first great wave of creative destruction in the PC industry was unleashed. See Figure 3, which shows the devaluation of inertial barriers to entry caused by advances in a complement and the resulting possibilities for entry and creative destruction.

\section{E. Mixed Incentives for Openness and Vertical Disintegration}

The early PC industry's open and modular design and its vertical disintegration had dual consequences. They led to the positive feedback cycle of invention and improvement in the PC itself and in applications. They also were important in enabling creative destruction. This duality is central to understanding performance in the PC industry.

There is a large difference in the private and social value of openness and vertical disintegration. Both parts of the duality, the positive feedback cycle and the creative 
destruction, benefited PC users. On the other hand, the incumbent firms selling CP/M and Apple IIs gained from the positive feedback cycle and lost from the creative destruction. (Entrants, on the other hand, gained from openness and vertical disintegration. Yet those structures were picked by the incumbents, not the entrants.) This gap between private and social incentives is essential to understanding the industry's history. It follows directly from the competitive nature of creative destruction, which looks better to society than to the existing firms whose rents are destroyed.

But let us be clear that the lesson here for Schumpeterian Economics is far more general than the narrow and specific point about "open architecture," which seems like a technical concept from computing. Instead, the point is about the role of a permissive, forward-looking system of innovation in which inventions can come from multiple sources. In short, it is about market innovation. Market innovation leads to increased social value. Uncontrolled market innovation means that existing firms sometimes get a large slice of that larger pie, and sometimes that they are the victims of creative destruction. Market innovation, like the competitive market system generally, is fabulous for consumers and a mixed bag for producers.

\section{F. Creative Destruction in Waves}

The sellers of WordStar and VisiCalc were instrumental in laying the groundwork for the wave of creative destruction, which quickly came to destroy their positions as well. The IBM PC led to a rapid increase in PC sales to corporations. That raised, substantially, the demand for spreadsheets and word processors. That was in the interest of spreadsheet and word processor sellers generally. Yet by lowering entry barriers it permitted the success of new competitors, which was not in the interest of the incumbent sellers of WordStar and VisiCalc.

The mechanism by which entry barriers fell in spreadsheet and word processor markets is specific to network effects markets. Each of VisiCalc and WordStar had enjoyed substantial entry barriers because of network effects inertia. A new spreadsheet or word processing user would choose the same product as the large installed base of existing users, sharing knowledge and files with them. The network effects advantages were substantial, so that entry even by a superior product would have difficulty succeeding.

That was changed by the rapid rise in the number of new spreadsheet and word processor demanders in the corporate world following introduction of the IBM PC. These new users were numerous, and worked in different kinds of firms than many of the early users. Rather than looking to the existing installed base of PC users for network effects, the new users could also look to one another. This change in the focus of network effects lowered entry barriers.

With lower entry barriers, superior products like Lotus 1-2-3 and WordPerfect entered the main applications markets and ultimately became the dominant products. The center of spreadsheet network effects moved to 1-2-3 and that of word processing network effects to WordPerfect.

The serious of events that led to the destruction of VisiCalc's and WordStar's position in a wave of new creation began with innovations in a complement that shifted out the demand for a particular product rapidly. Because of vertical disintegration, the nature, timing, and size of that shift were outside the control of incumbents. Rapid 
increases in the demand for a product that arise by bringing in new kinds of customers favor all sellers, but in a they particularly favor entrants in network effects markets. Entry barriers fell, and VisiCalc and WordStar were subject to new competition.

This parallels the series of events in creative destruction of the Apple II and CP/M rents. In each case, innovation in a complement shifted out demand and changed its composition. In each case, the lower entry barriers permitted new competition. In each case, the new competition led ultimately to a change in market leadership, with destruction of existing market positions and creation of new market positions.

\section{One Wave after Another}

These general lessons about creative destruction apply not only to the first wave surrounding the introduction of the IBM PC, but also to later waves of creative destruction in the PC industry.

The vertically disintegrated supply of the IBM PC made IBM a more rapid entrant with partial and backward compatibility, as we have just seen. In the early stages of the IBM PC era, the openness and modularity also served to encourage complementors, such as the new spreadsheet and word processors entrants Lotus and WordPerfect.

The greatest advantage of this structure to IBM came in getting established in the PC industry. Once the IBM PC was established as a standard, it was in IBM's interest to change to a less competitive structure. The vertically disintegrated structure and openness made the industry more competitive going forward. This was to the disadvantage of all incumbents, but particularly of IBM. ${ }^{\dagger+\dagger}$ This is a familiar and general story. Competition for the market gives suppliers incentives close to those of demanders. Ex post, established suppliers would like to prevent further competition.

The disadvantage to IBM of the openness and vertical disintegration came through entry and competition. Because of the open and modular design of the IBM PC, other firms were able to imitate it. Because of the vertical disintegration, the same other firms were able to gain complementors despite IBM's wishes to the contrary. In this section, we first look at why the openness and vertical disintegration were selfreinforcing, and then at how they encouraged competition.

The ex post disadvantages to IBM were advantages to consumers. The advantages to consumers came, in the first instance, because a modular and open design in an industry with many sellers of widely distributed products permits creative destruction and competition for the market. Let me begin with a few examples drawn from PC hardware. I focus on PC hardware because it was IBM's primary market.

\section{A. Divided Technical Leadership}

IBM set standards for connecting the IBM PC to display monitors. These were quickly seen as inadequate by customers and complementors. A number of monitors were introduced. Entrepreneurial Hercules entered with a monitor card that could be plugged into the PC. Hercules' card did not use IBM standards for connecting PCs and

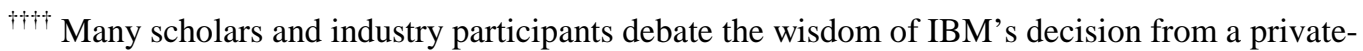
interests perspective. Little can be learned from this debate. IBM chose a risky strategy with large present benefits and large, uncertain future costs at the beginning of a wave of creative destruction. Bill Gates' view that the debate is merely backward-looking revisionist history may be found in Gates and Myhrvold (1995). 
monitors. Dominant spreadsheet firm Lotus quickly moved to support the Hercules standard, and made very popular versions of 1-2-3 that worked only with a card at least as functional as Hercules'. What had been part of the IBM PC standard for connecting monitors quickly became an industry standard.

Design standards inside the PC itself also moved outside IBM's control. Again the mechanism involved complementors who sought rapid technical progress and the vertically disintegrated structure of the industry. PC applications grew too large for the original IBM PC's limited memory. Applications developers complained about the limitation and pressed IBM for technical progress. Because of the industry structure, IBM was not the only firm that could provide that technical progress. IBM's complementors selling widely used products could do so. In the case of memory standards, it was not IBM, but complementors who introduced what was for a time the most successful design for adding large amounts of memory, the LIM standard - named after three firms, Lotus L), Intel (I), and Microsoft (M).

The lesson of the Hercules and LIM standards is a general one. As complex a technology as a PC contains many interface standards. There is a natural tendency to think of a single firm, such as IBM, as "the" standard setter. With vertical disintegration of widely used products and openness, however, there are multiple potential standard setters. A dominant firm in a particular market, even IBM, faces rivalry in the setting of standards and in their improvement. This is a powerful force for continuing openness once it has been established. This argument is an important part of the reason why Shane Greenstein and I called the structure of the PC industry "divided technical leadership.” 肺㧊

There are two directions of causation linking competition and openness in computing. We saw above that that there is a causal flow from openness and vertical disintegration to competition. In the last two sections, we have seen flows of causation in the reverse direction, in which competition causes openness and vertical disintegration. Competition for the market gave IBM an incentive to adopt open standards and vertically disintegrated structure at the beginning of the IBM PC era. Vertical disintegration in the most widely used products and the resulting divided technical leadership favored open standards once the IBM PC was established.

This solves a puzzle about incentives. If consumers gain from openness and vertical disintegration, and firms sometimes lose from them, why then did firms choose them? A firm may be compelled to, for competitive reasons, ex ante. The perspective of the firm ex post will be to wish to undo the vertical disintegration and openness in order to avoid competition. IBM certainly decided that ex post, and made a series of efforts to decrease the openness of the IBM PC and to increase vertical integration into key components. In the competitive race around the introduction of the IBM PC, however, the firm had strong incentives for openness and vertical disintegration. These features were key to its entering quickly and with a PC that was partially backward compatible. And, as we shall see, ex post competitive forces made it difficult to go back to a closed architecture. The gap between IBM's incentives and social incentives for openness was real, but competitive forces pushed IBM toward pro-consumer structures.

括㧊 See Bresnahan and Greenstein (1999). A body of formal theory addresses related issues. See, e.g., Farrell, Monroe and Saloner (1998). 
More generally, openness, vertical disintegration among widely used products, and dynamic competition can form a mutually-reinforcing system. This is why the early PC industry did not quickly revert to a model with closed proprietary standards and a vertically integrated dominant firm.

\section{B. Clone Competition}

The emergence of “clones” to compete with IBM was encouraged by the opennes and modularity and by the vertically disintegrated structure of the PC industry.

Modularity and openness lowered the fixed costs of competing with IBM. A clone PC manufacturer needed only to make only a PC. The many existing complements

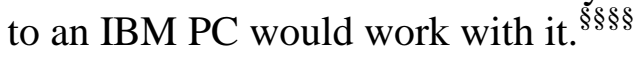

At first, customers viewed clones as inferior to IBM. How were users to be assured that a clone would be as reliable and well supported as an IBM, and how certain was it that the clone would run all IBM PC applications in the future as well as the present? This changed as, with the support of the widely distributed complementors, some sellers of clones began to eclipse IBM technically. The success of Compaq at shipping a PC that used a new Intel microprocessor, the 80386, before IBM did so is an important example.

This competition offered benefits to customers. It also offered benefits to IBM's complementors. They benefited from an increase in the rate of technical progress in PCs and competitive falls in the price of PCs. Complementors gained directly through having a better PC to work with, and indirectly by having a larger market.

A few complementors (such as Intel, Lotus, and Microsoft) with widelydistributed and influential products were in a position to encourage the development of clones. Since those complementors were vertically disintegrated from IBM, they had every incentive to encourage clones. These few complementors selling widely distributed products thus had both the opportunity and the incentive to encourage the emergence of clone competitors for IBM.

What had been an "IBM PC" standard became an "Industry Standard PC." Control of PC standard setting slipped away from IBM.

After a while, IBM attempted to regain control of the PC platform. The firm introduced new and improved standards for the interface for add-in cards, for networking, for a new operating system, and so on. It was, however, too late, as the industry standard PC was established and successful. The PC market itself became highly competitive.

No individual firm replaced IBM in the PC market, not Compaq with its technical advance nor Dell with its new and successful model of assembly and distribution. Instead, market supply of PCs replaced IBM. This is a distinct form of creative destruction. Many of the literal entrants were entrepreneurs, like Dell and Compaq, though others were established computer firms in the wider IT industry, like Hewlett Packard. They gained the support of IBM's complementors in the vertically disintegrated PC industry, and were able to offer customers a backward compatible and improved version of the PC that worked with many, many other complementary inputs. Creative destruction here is as far removed from action by a single Creator as is imaginable, and

$\S \S \S$ A system of compatibility testing grew up, with PC manufacturers and third parties offering assurances to consumers that buying a clone would get them something technically very similar to an IBM PC. 
the rents Destroyed at IBM were tiny compared to the aggregate possibilities for further growth.

The industry structure of the IBM PC industry had substantial advantages for PC customers. Much of its advantage to IBM was, however, ex ante. Ex post establishment of IBM PC network effects, IBM would have liked to, and attempted to, regain control of the standard so that it could block entry. IBM's inability to block entry contributed substantially to ongoing innovation and growth.

Many of the important firms involved in the early PC industry were consumed by creative destruction. The firms most important in triggering and carrying out the first wave of creative destruction, the sellers of WordStar, VisiCalc, and the IBM PC, were later consumed by creative destruction. The major applications vendors and IBM were both creators and among those whose positions were later destroyed. There were repeated changes in the industry's technical and market basis. When they were rapid, these changes led to occasions for creative destruction. While incumbent dominant firms lost, customers gained the opportunity to choose - at least during the wave of creative destruction - between the incumbents and new entrants.

One more round of rapid changes would lead to successful competition for the market against incumbent dominant firms in important markets.

\section{Precedents to another Wave}

Over the 1980s, the PC industry anticipated the invention of easier to use PCs. The diffusion of PCs into ordinary white collar work meant that less computerknowledgeable users were coming into the industry as customers. The key technical advance that would ultimately permit even wider use of the PC was the Graphical User Interface (GUI.) The mass-market, easy-to-use PC was long anticipated, but was not realized until the introduction of the GUI Windows version 3 in the early 1990s.

The successful Windows 3.0 was anticipated by many earlier but less successful efforts. A number of efforts to make PCs much easier to use were introduced starting from the first half of the 1980s, including GUI software from IBM, from Microsoft (Windows version 1, 2), from the sellers of VisiCalc and from entrant entrepreneurs. Like Windows, many of these products were positioned as complements to the IBM PC. None had any real success.

Other efforts to improve ease of use went forward within applications themselves. On the IBM PC and its clones, Lotus, WordPerfect, Excel, and Word all took on many GUI features. (Excel and Word came with an early "runtime" version of Windows.) Absent effective provision of ease-of-use by the most popular form of PC, applications suppliers provided it themselves.

The most successful GUI effort of the 1980s was Apple’s Macintosh. Introduced in 1984, it was not compatible with either Apple IIs or IBM PCs. Though more successful than other GUI efforts, the Macintosh was always was a distant second to IBM PCs (plus clones) in terms of demand.

The existence of Macintosh as a second-choice applications platform had several impacts. It gave users a distinct choice of products, with PCs offering lower prices and more choices of hardware and software but Macintosh offering greater ease of use. The existence of a reasonably successful second-choice PC standard, the Macintosh, meant that there were two platforms for business applications. On the Macintosh, the leading 
spreadsheet and word processor were Microsoft Excel and Microsoft Word, while on the IBM PC and clones, Lotus 1-2-3 and WordPerfect were the leading products.

We see once again that the important precedents for a wave of creative destruction arise in the marketplace. Their core is supply-demand mismatches. There was, in this case, little doubt about the long run direction of the industry toward greater ease of use. All important firms attempted to move in that direction, and all had limited success. There was, however, considerable doubt about the precise form of that long run change and about its timing. The ultimate transition came with Window 3.0. The previous history makes clear that this product was a triumph of commercialization and of implementation rather than a brilliant leap of invention.

\section{Consequences of a Wave}

The introduction of Windows 3.0 in the early 1990s marked the beginning of another wave of creative destruction in the PC industry. The leading applications vendors, Lotus and WordPerfect, were ultimately replaced. Technical change in a complement to those applications brought in a large number of new users, many distinct in demand characteristics from existing users. That lowered the entry barriers previously held high by network effects.

The success of Windows 3.0 increased the number of customers for PCs, and thus for the major applications categories. New users of PCs entered the market in large numbers. Their tastes for computing features were somewhat different than earlier IBM PC users, putting more weight on ease of use. Complementary advances in PC hardware, such as ongoing improvements in microprocessors, memory, and disk drive, meant that a cheap, GUI-based PC was now available. Windows based PCs were compatible with the earlier IBM PC and its clones, and thus could run IBM PC applications. These features meant that there was a large market for the new machines.

The implication of rapidly rising demand for the major applications categories was lowered barriers to entry. The network effects leading to inertia around WordPerfect and Lotus 1-2-3 were devalued.

Capable entrants were waiting in the wings. Word and Excel had been steadily improving as applications running on a machine with a GUI, the Macintosh. Once there was a popular GUI version of the PC, these products entered and competed very successfully against WordPerfect and Lotus.

There has been a loud debate in the PC industry about whether Microsoft, seller of both Windows and the entrant applications, behaved honorably in the wave of creative destruction in applications categories. ${ }^{+\dagger \dagger \dagger}$ We should ignore that debate for purposes of understanding the general analytical lessons of the applications creative destruction wave of the early 1990s.

Some of the major lessons are one we have seen before. Change in a complement played a large role in creative destruction, changing both long run and short run market conditions. Falls in entry barriers, rather than merely an entrant product overtaking an

\footnotetext{
${ }^{* * * * *}$ While at least Excel was clearly a better product than the market leading Lotus 1-2-3, Excel and Word were not even close to being leading products on the more popular IBM PC platform.

${ }^{+1+\dagger+}$ Microsoft was a partner with IBM in a competitive effort to Windows for a while, and both IBM and applications vendors said they were misled.
} 
incumbent one technologically or in suitability to the market, determined the timing of creative destruction.

Finally, the common identify of the seller of Word, Excel, and Windows does have analytical meaning. The moralistic debate about Microsoft's behavior in causing the transition from WordPerfect and Lotus to Word and Excel is irrelevant to the analytical meaning. One consequence of this wave of creative destruction was that vertical disintegration among the widely distributed products in the PC industry was reduced. Among widely distributed and influential software products, it was reduced to zero. Microsoft had been the dominant operating system seller for a long time. Now Microsoft was also the seller of the most important widely distributed applications. This changed the structure of the PC industry in a critical way. There has not been another wave of creative destruction in the interim.

\section{E. The Origins of Entrants}

Where do entrants come from? This question is a stepchild in Economics generally. Analysis at the firm level answers this question badly. We cannot answer it merely by talking about the creative genius of entrepreneurship. We cannot answer it by taking the perspective of the incumbent dominant firm, surprised by the new market or technical conditions which support entry. Entrants in industries that involve cumulative investment do not come out of nowhere; they come out of somewhere.

Word and Excel came out of the second-place PC of the earlier era, the Macintosh. Those products had had a profitable history, though in a far smaller market than WordPerfect and Lotus had on the IBM PC. Further, they were sold by a firm, Microsoft, who could see the advantages of entering and competing for the market. At the time of its successful entry into the business applications market in the early 1990s, Microsoft was a fifteen year old entrepreneurial firm; its efforts to enter the largest and most profitable applications markets had been failing for ten of those fifteen years.

Here, as in the earlier entry of IBM, we see the advantages of a large diverse information technology sector serving many different kinds of users. Firm reputation capital built up in related markets (IBM in corporate data centers) or product designs built up outside of the largest and most competitive markets (Word and Excel on Macintosh) are slowly-growing assets for entrants. A diverse IT sector permits investments in these assets for one purpose; repositioned for another purpose in another market, they become entrants.

Prior investment point is particularly important when competition for the market goes quickly compared to the rate at which firms can invest in new technologies and new modes of commercialization. While waves of creative destruction sometimes take a period of time in PC markets, that is usually because of supply constraints, and participant firms are almost always better off if they have made a subset of the appropriate prior investments.

Other important PC entrants were entrepreneurial firms. All the firms in the 1970s, as I pointed out above, were entrepreneurial. Many of the important entrants in the 1980s, such as Lotus, WordPerfect, Compaq, and Dell, were entrepreneurial as well. Similarly, many of the thousands of other important suppliers of PC hardware and software of the 1980s and 1990s not covered explicitly in this paper were entrepreneurial startups. 
When the nature of demand and technology are changing over time, creative destruction can replace existing firms and products with new ones. When it is difficult to understand exactly what kind of firm or product will work well in the future, there is a

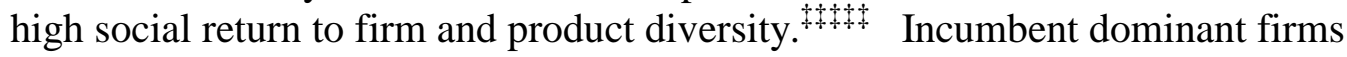
contribute to that diversity; entrepreneurial startups contribute to that diversity; firms from elsewhere in the computing and communication industry contribute to that diversity; and finally, firms already in the PC industry in one market migrating to another market contribute to that diversity.

The combination of a diverse set of potential entrants and repeated waves of creative destruction meant that PC markets had effective competition for the market from the founding of the industry in 1975 through the early 1990s.

\section{IV.A Wave Rebuffed: Sea Change or Seawall?}

There has been one more occasion for a new wave of creative destruction, the widespread use of the Internet. A new and even larger market for the PC opened up as a result of new online technologies, notably the WWW and the browser. Entrepreneur Netscape commercialized the web browser, starting a wave of entrepreneurship and opportunity that surprised PC industry incumbents. No new competition came to the established PC categories, however. In this section I examine first the causes of this wave and then its (lack of) consequences. ${ }^{\text {}}$.§§§

\section{A. Precedents to a Wave}

In the mid 1990s, after the establishment of Windows, the leading platform for PC applications was "Wintel," i.e., a PC of any brand running Microsoft Windows on Intelarchitecture chips. To achieve backward compatibility with industry standard PCs, early Wintel machines (e.g. those running versions 3.0 and 3.1 of Windows) involved a number of design compromises. The next version, Windows 95, was a big step forward. Nonetheless, throughout the mid and late 1990s, Wintel machines drew complaints from complementors and corporate customers. Two main complaints stood out; an acute problem of high "total cost of ownership," i.e., high maintenance and update costs once a Wintel machine was installed. The second problem was chronic; it was then, as before, difficult to network Windows machines.

For Microsoft, there appeared to be time to solve these problems. No widely distributed complementary product was in a position to create a wave of creative destruction. Accordingly, the firm undertook to solve the problems of Windows by a series of incremental and largely backward compatible steps that would lead customers from the industry standard PC of the late 1980s to the much more capable machines of the twenty first century.

Intel faced a somewhat different problem with the future of Wintel machines. The transition to the more graphical Windows and to more graphical applications

持执 This is the central point of Cohen and Malerba (2002).

$\S \S \S \S \S$ This section draws on materials made public in connection with the Microsoft antitrust trial in the US. I worked in the Antitrust Division during that trial. It also draws on the research and journalistic literature about the antitrust trial and about firms in this era, notably Bank (2001), Ferguson (1999), and Cusumano and Yoffie (1998), and on the research and journalistic literature about Microsoft as a company, notably Cusumano and Shelby (1995), Stross (1997), and Manes and Andrews (1993). 
programs gave users a reason to upgrade their computer hardware, continuing a twodecade trend. Intel was seeking to enable new innovations in applications, possibly in the area of multimedia or entertainment, to continue the trend into the future. Intel also faced a somewhat different competitive environment than Microsoft, with cloner AMD posing a real competitive threat.

\section{Anticipatory Innovations}

Firms in the PC industry, like those in the broader communications and computer industries, had long anticipated the applications we now associate with the Internet. For years before the widespread use of the Internet, they saw the benefits of connecting very large numbers of people to online resources. They saw the benefits of a universal commercial network connecting computers in markets. The diffusion of the PC to most white collar desks, and the creation of vast amounts of online data and information, increased the potential benefits of connectivity. The possibility of connecting computer networks to people at home for entertainment or marketing (electronic commerce) purposes had also been visible for some years.

Before the widespread use of the Internet, a wide number of distinct technologies were introduced in order to support those "online" applications. Some were top-down initiatives led by powerful central forces like a telephone company, a government, or a private-public consortium. These were mixed in success, with results ranging from nothing up to limited success - Minitel in France was probably the most successful in reaching a mass market. Others were proprietary, closed systems pushed by a single vendor. These varied, too, with limited success for some Electronic Data Interchange products for business-to-business electronic commerce and for AOL on the mass market side.

Of all the PC, computer and communications firms, one had a strategy for online applications which is particularly well documented. That is Microsoft, whose internal debates about online applications were made public as a result of a lawsuit. In the era before the commercialization of the browser, that firm confined its attention to proprietary, closed systems for linking the online world to the PC. Even as an "Internet mania" came to Microsoft's attention in 1994, it remained determinedly focused on a closed and proprietary online approach. Yet Microsoft is merely the best documented. Before the commercialization of the browser, many existing commercial computing and telecommunications firms attempted to supply general purpose technologies for connecting to the online world that did not ignite mass market online applications.

The last precursor for the surge of online applications we actually saw in the late 1990s was the Internet itself. That technology advanced in military, government, university and related sites for twenty years without ever gaining mass use or its present commercial importance.

\section{B. Beginnings of a Wave}

Two steps were very important in making the Internet a mass market technology, the World Wide Web (WWW) and the (web) browser. These are general purpose technologies that were invented with specific purposes in mind. The WWW was first invented as a way for high energy physicists to share data and results. It was designed to be open and general. The WWW led to a number of useful inventions within the low- 
value walls of academe. One of these was the browser, which put a simple graphical user interface on the WWW. Another general purpose technology invented with a specific purpose in mind, the browser was also open and general.

Entrepreneur Netscape commercialized the browser. This was recombination on a grand scale. The mass market commercial browser was a new complement to several existing assets. It was a complement to the WWW and the Internet. It was also a complement to the commercial PC and to the vast amounts of commercial data stored on large computers.

The browser was a modular component. It worked with the existing WWW and Internet. Netscape's commercialization strategy was to write browsers that worked with all kinds of PCs. This offered browser users backward compatibility. They could continue to use their existing PC and have access to a great deal of online information. To get access to a wide variety of information from a wide variety of sources stored on a wide variety of different computers, the user had only to get one piece of software, the browser.

Invention and commercialization of the browser dramatically raised the demand for PCs. PC users had easy access to new online information if they had a browser. An "Internet mania" grew up, in which there was a great deal more information on the WWW because there were more WWW users, and more users because there was more information. These network effects led to rapid growth, and the browser became a very successful PC application.

Once they were online, users began to demand communications applications such as email, online entertainment, wider opportunities to shop, be entertained and be informed. sharing photos, instant messaging, and so on. Here the second advantage of the modular and open WWW and browser came into play. A provider of information, entertainment, or services to consumers did not need to set up an online network to connect to them. Nor did they need to form a contractual relationship with some kind of proprietary service. Instead, they needed only to connect their computer to the Internet. Major technical and organizational barriers to the supply of networked content and applications had been removed. More complex network effects between online applications and users began to form.

These new applications made PCs far more attractive to some classes of potential users, such as communications oriented home users, than they had been earlier. The demand for PCs grew rapidly. The new users of PCs were different from the white collar workers who had been the mainstay of PC demand for a decade an a half. Ironically, they were closer to the users originally forecast for the PC back at the beginning - home users, multimedia users, communications users, and so on.

These are exactly the kinds of developments that had triggered waves of creative destruction earlier in the history of the PC industry. Existing PC industry dominant products, such as the applications Word and Excel (by now combined into Office) or the Windows operating system, would have their network effects devalued by the rapid arrival of a large number of new users whose demand was distinct from existing users. From the perspective of the Windows operating system, the arrival of a large class of new applications - online ones - threatened to devalue its network effects even further. Just as we saw in earlier waves of creative destruction, the browser both raised the demand for 
the PC by recombining it and opened new competitive threats to existing PC dominant firms and products.

\section{Reactions of Existing Firms}

Many existing computer and telecommunications firms embraced the new opportunity. For example, Sun, manufacturer of computers used as "servers" in networks, introduced a new applications development platform called Java.

The PC industry firms with widely distributed products were reduced to two, Intel (microprocessors) and Microsoft (operating system and widely distributed applications.) They responded to the new opportunity very differently.

Intel embraced the Internet as an opportunity to work with a new class of complementors. They formed an alliance with Sun, sellers of Java, for example, whose goal from an Intel perspective was to encourage development of a number of new, microprocessor-intensive, applications for PCs. (Java's virtues did not include economizing on microprocessor activity.) They sought to add multimedia features to their microprocessors to support new, consumer-oriented applications. They benefited from a remarkable increase in the demand for PCs as the new home and communicationsoriented market segments took off.

Microsoft, by contrast, decided that the potential wave of creative destruction was a threat to its dominant position in the operating system and in major applications. The widespread use of the Internet would raise demand for Microsoft's products. Yet the rapid change brought about by innovation in a complement, the browser, was also a problem for Microsoft, along the lines we have seen throughout this paper.

Microsoft diagnosed two problems. First, the open and modular structure of the WWW and the browser posed a competitive threat to Microsoft. The loss of control of standards to connect PCs to the online world was the first thing troubling Microsoft; rapid innovation by a large number of different firms, they reasoned, could lead to the setting of open standards. With a successful browser sold by an independent firm would come recreation of a vertically disintegrated structure for the PC industry. Microsoft feared the restoration of the competitive situation that long had prevailed in the PC business.

The second thing that troubled Microsoft was the potential fall in entry barriers if products and technologies like the browser and Java were to succeed. There was an imminent threat of falling entry barriers as new and diverse users came into the PC market. Entrants were waiting in the wings; Linux, for example, had advanced considerably serving a very different kind of customer than PCs.

To make matters more difficult for the incumbent dominant firm, new applications invention was opening a gap between the existing PC and the PC that new customers would really like - just as the invention of the word processor and the spreadsheet had, earlier. Once again, the gap between what existing PCs could do and the desires of the newest demand segment gave the incumbent dominant firm a difficult technical and business problem.

The possible reversion to open standards and vertical disintegration were discussed in extensive detail inside Microsoft. So, too, was the threat of new competition 
from lowered entry barriers, and the gap between Microsoft's existing products and what the growing demand segment.

\section{End of a Wave}

The potential wave of creative destruction in the PC business set off by the widespread use of the Internet did not occur. Rather than failing, it was blocked.

While it had been entirely surprised by the success of the browser, once Microsoft saw the threat it responded alacrity, energy, and focus. The threat of creative destruction gives the established firm powerful incentives.

Microsoft reacted to two powerful incentives. First, as Schumpeter emphasized, the threat of creative destruction gives powerful innovation incentives. Microsoft recognized a second incentive, which is that preventing the competitive threat of creative destruction can preserve a dominant position. Microsoft went down both paths, with very different results.

The first path illustrates the differences in resources and capabilities between an established dominant firm and an entrepreneurial startup. Microsoft moved thousands of people into a new division to compete with Netscape. Working rapidly, that division eventually succeeded in catching up to Netscape in product quality. The catchup was too little and too late, however, for Microsoft to eclipse Netscape. Marketing officials in both firms observed at the time that Microsoft's browser quality improvements were insufficient in and of themselves. ${ }^{\dagger+\dagger+\dagger}$

This was a remarkable stretch of business history. There is little surprise in the observation that an entrepreneurial entrant, Netscape, opened up a new market ignored by an incumbent dominant firm, Microsoft. What is surprising is that, even after Microsoft counterattacked in full force, it was unable to win the browser standard setting race against the newly founded entrepreneurial firm. Even against the superior resources and capabilities of an established and successful firm, and even after the key activities shifted to commercialization and to incremental improvements, the innovativeness of the entrepreneurial firm won out.

Microsoft reached the conclusion that it could not succeed in the effort to set browser standards merely by innovating in its own product. It needed to do more to avoid creative destruction.

Microsoft's second path was to prevent independent outside creation in order to avoid destruction. Microsoft first made contractual offers to Netscape and Sun, the sellers of Java, to avoid the threat of competition (as basic cartel theory predicts it should have). Sun accepted on the condition that Microsoft work with standard (non-Windows-only) java, only later to sue claiming that Microsoft had violated the contract. ${ }^{\ddagger \neq \neq \neq \ddagger}$ Netscape declined, anticipating that a contractual collaboration would weaken their position.

****** I have quoted some of the internal discussion along these lines in Bresnahan (2001) and in Bresnahan (2002) I am the second person to analyze the PC industry along the lines of this paper. The first, Bill Gates, who is quoted in the cited papers, has made several tens of billions of dollars more than I from this knowledge.

t+t+t+ The new division was shut down and the browser effort moved into the division that sells

Windows after this became clear.

㧊㧊 The suit was recently settled with a large payment to Sun. 
Having failed with its own product and with the offer of contract, Microsoft then prevented the widespread distribution of the Netscape browser (and Sun's java ${ }^{\S \S \S \S \S \S}$ ) and prevented third-party complementors from working with Netscape (or with Sun's java). Crucial distributors, such as manufacturers of PCs and Internet service providers, were blocked from distributing the threatening technologies. Complementors such as applications developers and even Intel were block from technical collaboration with sellers of the threatening technologies.

One reason Microsoft could compel other firms not to work with entrants was that the openness and vertical disintegration of the PC industry had declined. Windows was less open than earlier PC operating systems had been, for Microsoft kept the information about interaction with Windows under tight proprietary control. While it gave that information out to many complementors, it could withhold the information from firms who cooperated with the Internet entrepreneurs. Second, the only firm selling a very widely distributed software product in any of the markets listed in Figure 1 was Microsoft.

Microsoft's effort on this second path succeeded. Without widespread effective distribution, the independent browser and java failed. Without widespread distribution and many complementors, mass-market network effects could not take root.

Microsoft's actions on the second path were illegal under the antitrust laws, but that is not important for our current inquiry. The important lesson for our present inquiry is not how the opportunity for creative destruction was blocked but merely that it was blocked.

The blocked distribution of the Internet innovators meant that the threatened wave of creative destruction never came to pass. The failure of the Internet revolution to reestablish vertical disintegration in the PC industry also means that the conditions for another wave of creative destruction are unpromising today.

\section{Lessons of blocked creative destruction}

Microsoft's successful effort to block creative destruction competition against its dominant positions carries the same analytical lessons as do earlier waves of creative destruction that succeeded. Creative destruction is not in the interests of established dominant firms. Microsoft blocked the widespread distribution of products subject to network effects to stifle one wave of creative destruction. It also prevented reestablishment of the vertical disintegration of widely used PC products and technologies which could have led to new waves of creative destruction.

Would Microsoft's Windows or Office have been swept away by creative destruction if the distribution of threatening new technologies had not been blocked? This question cannot reasonably be answered either yes or no. The disruptive changes associated with the browser and java would have lowered entry barriers into the operating system and business applications markets. Whether an entrant or entrants would have succeeded is unsure, one too many steps away from the historical record.

\footnotetext{
§§§§§ Sun’s lawsuit asserted that Microsoft distributed its own version of Java in violation of the contract. While the European Union's decree in the Microsoft case is pro-consumer, it falls far short of reestablishing competitive conditions in the PC industry. The earlier US decree is ineffectual.
} 
At a minimum, as Schumpeter emphasized, an entrant or entrants would have put valuable competitive pressure on Microsoft to innovate in a pro-consumer direction, pressure that has been lacking since the end of the browser war in 1998.

\section{Conclusion}

Any study of creative destruction in the PC industry should answer two basic positive economics questions. Why were there a series of waves of creative destruction in this industry over two decades? Why did creative destruction cease?

The first question is answered by the interaction between entry barriers in PC industry markets and the vertical disintegration of supply of widely used products and technologies. Network effects lead to entry barriers around established products. Under vertical disintegration, technical progress in complements can lower entry barriers. That technical progress goes forward whether a particular established firm thinks of it or not and whether it is in their interest or not. That explains the inventive power of the industry, with innovation in widely distributed components spread over a large and diverse body of firms. It also explains the creative destruction. Vertical disintegration over the first twenty years of the industry enhanced the rate of innovation; it enhanced it partly through a Schumpeterian process, repeatedly destroying the rents of established firms.

The waves of creative destruction ended with the decline, in the 1990s, in vertical disintegration of widely used PC products and technologies. The widespread use of the Internet threatened to restore the industry to its more innovative and competitive form by adding new markets and vertical disintegration among the widely used products, but that was not to be.

In making this argument, I am implicitly discarding several ideas. One story of declines in creative destruction might be maturation. That would mean that creative destruction ceased because opportunities for it disappeared. A related maturation story would be that, after a series of trials, the market had selected the best firms for all products. Both of these maturation stories are belied by the events surrounding the widespread use of the Internet, where outsiders invented and commercialized important new technologies. Outsider supply was still far too important for this to be a time of maturation.

A second idea I am discarding - more a habit of mind than an idea, really - is that the boundaries of the firm are determined entirely by the efficient organization of supply. Vertical integration of widely used products in the PC industry matters for more than just the efficiency, either static or dynamic, of the products and technologies that might be supplied together or separately. Instead, vertical disintegration lowers entry barriers, permitting creative destruction.

There is a very general point there. Whatever the conditions supporting creative destruction in any industry, suppliers and demanders have a gap in their incentives. Both suppliers and demanders benefit from the value-increasing part of creative destruction. There is a gap between supplier and demander incentives insofar as conditions change to permit competition that destroys producer rents - and creative destruction is a great destroyer of producer rents. In the PC industry, this means that the value of vertical 
disintegration within the widely distributed products is higher for consumers than for

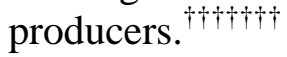

A third idea I am discarding - really another habit of mind - is that the timing of waves of creative destruction can be entirely explained by the comparing incumbent dominant firms to outsiders. In the PC industry, superior technology or market organization by outsiders is necessary but not sufficient for creative destruction. Instead, entry barriers must fall as well.

Caution is advisable in drawing general lessons about creative destruction from any industry study. Caution is all the more advisable here since the PC industry is extreme in several dimensions, including the pace of technical change. An advantage of looking at the PC industry is that the intervals between opportunities for creative destruction have been short in calendar time because of the rapid pace of change.

Why has vertical disintegration been so important for creative destruction? There are general lessons in that. Many of the critical transitions in the PC industry followed a circuitous route in which decentralized invention of complements moved the industry from one role to another in incremental steps. That is, decentralization of invention lead to recombination.

The importance of decentralization provides a positive explanation of recombination. Many scholars, from Adam Smith to Schumpeter to our own colleagues, have made the normative argument that recombination of existing technologies is a valuable form of technical progress. From a positive economics perspective, recombination is linked to decentralization among innovators. To be sure, recombination economizes on the past stock of invention by re-using it (the normative theory.) Recombination also economizes on knowledge about the future direction of technical progress; decentralization and ex post flexibility rather than on plan or contract create the circuitous path to recombinant growth.

In the PC industry, attempts at creative destruction rarely come solely from the inventiveness of the entrant. Instead, cumulated change in complementary products and technologies leads, through recombination, to a long run opportunity for an improvement. Rapid change in complementary products and technologies lowers entry barriers, creating immediate opportunities for entry and competition for the market.

That helps explain the high rate of creative destruction in the PC industry over its first twenty years. A PC is a system made up of many different technologies and products. From the perspective of any single technology or product, there are a number of external changes accumulating, and a number of potential loci for rapid innovation that creates new entry opportunities. The PC industry is obviously extreme both along that dimension and in the frequency of creative destruction in its early days. Yet it is clearly a general point that economic organization that permits decentralization in invention can lead toward creative destruction.

Why do established firms miss waves of creative destruction? Part of the answer in the PC industry is that some waves are very difficult to foresee. To the extent that a wave of creative destruction involves a circuitous route through a number of inventive steps, it is not foreseen by any firm. The decentralized invention process open to all

${ }^{+1+1+\dagger+}$ Vertical disintegration of niche products, such as software applications for narrow groups of users, is in the interest of both sellers and buyers in this industry. 
firms in the economy dominates a single firms' efforts. Central planning, whether by governments or by a single established firm, is dominated by the market system.

When that has not been the explanation, the problem facing incumbent dominant firms has sometimes been that they have the wrong knowledge, and sometimes that they have the wrong incentives. Yet the sense of wrong knowledge and the sense of wrong incentives are subtle. For example, the applications dominant firms of the late 1980s knew that a transition to an easier-to-use PC was coming; it was the time, form, and suppliers of that transition they could not foresee (to their peril.) Similarly, Microsoft forecast the transition to a market in which PCs were connected online; it was the value of the Internet specifically, and of an open and modular approach to online connection, that they missed. In the PC industry, many waves have been difficult to foresee in adequate detail to guide firm strategy.

These examples, and the others we have seen, push us away from a simple answer to whether we need creative destruction because established firms are inadequately innovative or have limited incentives? Competitive supply has two long-established advantages in economics. It gives suppliers better incentives. It also takes advantage of the capabilities of multiple firms. Creative destruction competition is like other competition in this regard.

Creative destruction in the PC industry is preceded by fundamental changes in the supply-demand match. The change often arises from technical progress in a complement. We have seen a number of occasions on which technical progress in applications led to a mismatch between supply and demand in general purpose components of the PC. We have also seen occasions on which progress in the GPT components realized applications mismatches, and occasions on which progress in some GPT components realized mismatches for other GPT components. The essential feature of all of them is that technical progress in a complement can change the market situation of a particular product. Thus, to understand creative destruction in one PC market, one must look at other PC markets. One implication is that the entrants themselves are not the only creators behind creative destruction in the PC industry. The innovations by complementors that create new opportunities and lower entry barriers are central. The generality of this particular point will vary with the degree to which markets are linked. Another implication is that vertical disintegration and open systems support creative destruction, while vertical integration and proprietary system are an impediment to it. Creative destruction has conditions. We can analyze when it is likely to happen. It is not merely the limits on human brilliance that matter (though of course they do.) Instead, there are long run supply and demand issues. There are short run entry barrier issues. There are, of course, issues of the relative capabilities of incumbents and entrants. All of these are amenable to analysis. Some of the elements of that analysis are specific to industries (like the PC here) while others are general.

In the PC industry, we should understand the timing of creative destruction as being driven by two forces. One is the forces for stasis associated with existing positions. The other is technical progress that enables new positions. At that level of abstraction, the point is perfectly general. What the PC example brings to the fore is that the force for stasis is not only efficient assets accumulated by existing firms, but also entry barriers associated with their status as incumbents. 
Creative destruction occurs in markets. That is not a statement of the answer; it is a statement of the question. We need to undertake market analysis to understand creative destruction. But we can. Perhaps the most general and important general point from the PC industry is that the analysis of market competition and the analysis of creating value by introducing new goods into markets takes us so far in understanding creative destruction. 


\begin{tabular}{|c|c|c|c|c|c|}
\hline Market $\quad$ Era & 1970s & 1980s & & 1990s & Today \\
\hline Word Processor & WordStar & WordPerfect & & MS Word & MS Word \\
\hline Spreadsheet & VisiCalc & Lotus 1-2-3 & & MS Excel & MS Excel \\
\hline $\begin{array}{l}\text { Programming } \\
\text { Tools }\end{array}$ & MS & MS + Borland & & MS & MS \\
\hline Browser & & & & & MS IE \\
\hline Operating System & $\mathrm{CP} / \mathrm{M}$ & $\begin{array}{l}\text { IBM PC-DOS } \\
\text { MS-DOS }\end{array}$ & MS-DOS & MS Windows & MS Windows \\
\hline$\overline{\text { Box }}$ & Apple + Many & IBM & IBM+Clones & Many & Many \\
\hline Microprocessor & Intel+Zilog & Intel+AMD & Intel+AMD & Intel+AMD & Intel+AMD \\
\hline
\end{tabular}

Figure 1 Leading Products and Firms in Widely-Used PC Markets 


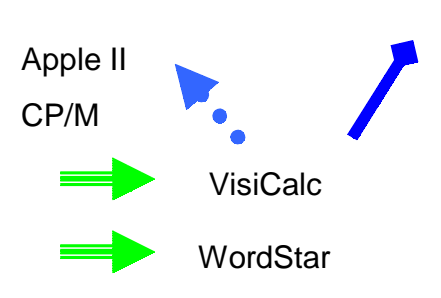

Enables

A general purpose technology invention enables applications inventions not foreseen by the GPT inventor.

Distributed information

Expands Demand
A new application expands the
demand for a GPT by making it
useful to a new group of customers.
Sometime, a large new market.

Figure 2 Positive Feedback 


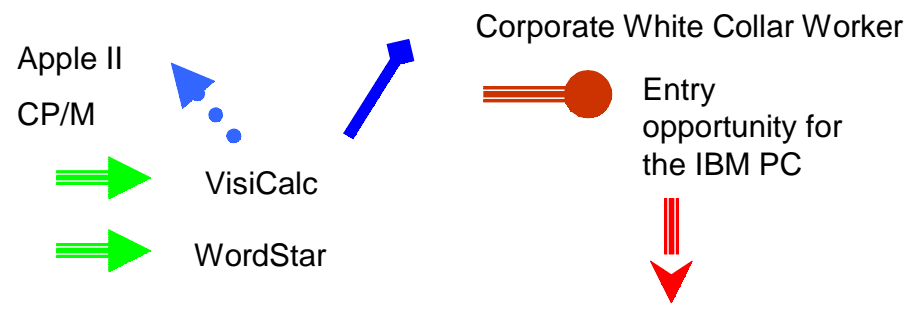

CP/M: Rapid decline

Apple II: Decline

Overcoming Network Inertia

A large new market for a GPT devalues network effects in existing networks.

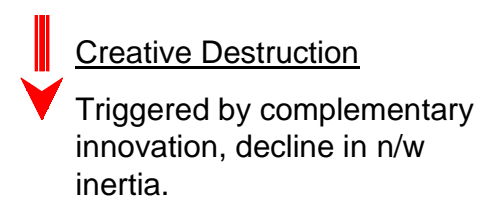

Figure 3 Triggers of Creative Destruction 


\section{Bibliography}

Bank, David. 2001. Breaking Windows : how Bill Gates fumbled the future of Microsoft. New York: Free Press.

Besen, S. M. and Farrell, J. "Choosing How to Compete: Strategies and Tactics in Standardization." Journal of Economic Perspectives, Vol. 8 (1994)

Bresnahan, T. (2001) "Network Effects and Microsoft” available at www.stanford.edu/ tbres.

Bresnahan, T. (2002) "The Economics of the Microsoft Case” available at www.stanford.edu/ tbres.

Bresnahan, T. and Greenstein, S. "Technological Competition and the Structure of the Computer Industry." Journal of Industrial Economics, (1999).

Campbell-Kelly, Martin, and Aspray, William. 1996. Computer: A History of the Information Machine. New York: Basic Books.

Chandler Jr., Alfred D. (2001) Inventing the Electronic Century: The Epic Story of the Consumer Electronics \& Computer Science Industries. New York: Free Press.

Christensen, Clayton M. The Innovator's Dilemma 1997, Harvard Business School Press.

Cohen, Wesley M., and Franco Malerba. 2001. Is the Tendency to Variation a Chief Cause of Progress? Industrial \& Corporate Change 10, no. 3:587-608.

Cusumano, Michael A., and Selby, Richard W. 1995. Microsoft secrets: how the world's most powerful software company creates technology, shapes markets, and manages people. New York: Free Press.

Cusumano, Michael A., and Yoffie, David B. 1998. Competing on Internet time: lessons from Netscape and its battle with Microsoft. New York, NY: Free Press.

Evenson. R. and Y. Kislev. “A Stochastic Model of Applied Research.” Journal of Political Economy, Vol. 84 (1976), pp. 265-81;

Farrell, Joseph, and Paul Klemperer. 2001. Coordination and Lock-In: Competition With Switching Costs and Network Effects. Handbook of Industrial Organization 3 (forthcoming!!), 1-90.

Farrell, Joseph, Hunter Monroe, and Garth Saloner, "The Vertical Organization of Industry: Systems Competition versus Component Competition” Journal of Economics \& Management Strategy 19987 (2)143-82

Ferguson, C. "No Prisoners,: a winner's tale of greed and glory in the Internet wars." Times Business, New York (1999).

Fleming, Lee. 2001. Recombinant Uncertainty in Technological Search. Management Science 47, no. 1:117-132.

Freiberger, Paul, and Swaine, Michael. 2000. Fire in the Valley: the Making of the Personal Computer.2nd ed. New York: McGraw-Hill.

Gans, Joshua, David Hsu, and Scott Stern. 2002. When Does Start-Up Innovation Spur the Gale of Creative Destruction? RAND Journal of Economics 33, no. 4:571-586.

Gates, B., Myrhvold, N., and Rinearson, P. The Road Ahead Viking: New York, 1995.

Henderson Rebecca, and Kim B. Clark (1990) "Architectural Innovation: The Reconfiguration of Existing Product Technologies and the Failure of Established Firms," Administrative Science Quarterly, 35 (1990): pp. 9-30, 
Henderson, Rebecca (1993) "Underinvestment and Incompetence as Responses to Radical Innovation: Evidence from the Photolithographic Industry”, RAND Journal of Economics, v 24, n 2, pp. 248-270

Katz, M. and Shapiro, C. "Systems Competition and Network Effects." Journal of Economic Perspectives, Vol. 8 (1994), pp. 93-115.

Langlois, R. N., and Robertson, P.L. "Networks and Innovation in a Modular System: Lessons From the Microcomputer and Stereo Component Industries." Research Policy, Vo. 21(1992), pp. 297-313.

Langlois, Richard, “Modularity in Technology and Organization,” Journal of Economic Behavior and Organization, 2002.

Liebowitz, S. J. and Margolis, S. E. Winners, Losers and Microsoft: Competition and Antitrust in High Technology Independent Institute,1999.

Liebowitz, S.J., and Stephen E. Margolis, "Network Externality: An Uncommon Tragedy," Journal of Economic Perspectives, 8 (Spring 1994), pp. 133-150.

Manes, Stephen, and Andrews, Paul. 1993. Gates: How Microsoft's Mogul Reinvented an Industry--and Made Himself the Richest Man in America.1st ed. New York: Doubleday.

Metcalfe, J. S. 1998. Evolutionary economics and creative destruction. Vol. 1. London ; New York: Routledge.

Nelson, R.R. "Uncertainty, Learning, and the Economics of Parallel Research and Development Efforts” in E. Mansfield and E. Mansfield, ed., International Library of Critical Writings in Economics, Vol. 31 (1993), pp. 444-57.

Nelson, Richard R., and Winter, Sidney G. 1982. An evolutionary theory of economic change. Cambridge, Mass.: Belknap Press of Harvard University Press.

Reinganum, Jennifer F. 1989. The Timing of Innovation: Research, Development, and Diffusion. In Handbook of Industrial Organization, edited by Richard L. Schmalensee and Robert D. Willig. New York: Elsevier Science Publishing Co., Inc.

Schmalensee, Richard L. (2000), “Antitrust Issues in Schumpeterian Industries,” American Economic Review, 90 (May), pp. 192-196.

Schumpeter, Joseph Capitalism, Socialism, and Democracy, (1942), pp. 82-85 (page cite to 1975 Harper edition.)

Schumpeter, Joseph, The Theory of Economic Development, (1911).

Shapiro, Carl, and Varian, Hal R. 1998. Information Rules: A Strategic Guide to the Network Economy. Boston, MA: Harvard Business School Press.

Stross, Randall E. 1997. The Microsoft Way: The Real Story of How the Company Outsmarts its Competition. Reading, MA: Addison-Wesley.

Varian, Hal R. July 2001, Revised March 30, 2003. Economics of Information Technology.

Veblen, Thorstein. 1904. The theory of business enterprise. New York: C. Scribner's Sons.

Weitzman, Martin L. 1998. Recombinant Growth. Quarterly Journal of Economics 113, no. 2:331-360. 